\title{
$\mathrm{O}$ direito face ao risco
}

Risk and the Law

Le droit face au risque

\section{Catarina Frade}

\section{OpenEdition}

\section{Journals}

Edição electrónica

URL: http://journals.openedition.org/rccs/220

DOI: $10.4000 /$ rccs. 220

ISSN: 2182-7435

\section{Editora}

Centro de Estudos Sociais da Universidade de Coimbra

\section{Edição impressa}

Data de publição: 1 Setembro 2009

Paginação: 53-72

ISSN: 0254-1106

Refêrencia eletrónica

Catarina Frade, " 0 direito face ao risco », Revista Crítica de Ciências Sociais [Online], 86 | 2009, colocado online no dia 01 dezembro 2012, criado a 20 abril 2019. URL : http:// journals.openedition.org/rccs/220 ; DOI : 10.4000/rccs.220 


\section{CATARINA FRADE}

\section{O direito face ao risco}

Emergindo da tradicional dicotomia entre concepções objectivistas e construtivistas do risco, quer as abordagens quantitativas, quer as teorias sociais do risco oferecem as suas interpretações dos problemas oriundos do progresso tecnológico e científico que vêm desafiando a segurança das sociedades contemporâneas. O objectivo principal deste texto é perceber como o risco é interpretado por diferentes áreas do conhecimento e como se pode perspectivar uma leitura jurídica desse mesmo fenómeno, dado que a ciência jurídica continua a manter-se algo alheada destes debates, esquecendo a sua missão reguladora e a sua vocação securitária.

Palavras-chave: Direito, risco, regulação, ciência, sociedade do risco.

\section{Introdução}

No seu sentido etimológico, o termo risco deriva do italiano risicare, que significa ousar. Ousar não constitui uma fatalidade, antes uma opção perante a oportunidade de obter maiores benefícios. Nesta perspectiva, o risco é encarado de forma positiva, como uma expectativa de ganho pelo simples acto de se arriscar, de se optar por 'ir a jogo'.

No entanto, o conceito de risco privilegiado pelas teorias do risco refere-se à probabilidade de ocorrência de efeitos nefastos, adversos (Leiss e Hrudley, 2005: 4; Hood et al., 2001: 3). Segundo Rohrmann e Renn (2000: 14), o risco pode ser definido como a possibilidade de um dano ou perda física, social ou financeira devida a um determinado perigo, num dado momento. O risco diz respeito a perigos externos, tais como catástrofes naturais, e a perigos induzidos (Giddens: 2000: 35; 1998: 27-28), como catástrofes tecnológicas e outros comportamentos potencialmente lesivos dos seres humanos (Ericson e Haggerty, 1997: 3). O risco é a possibilidade de uma realidade que é o dano. É um fenómeno em processo de se tornar real, um "becoming-real", nas palavras de Beck (2000: 165).

Embora o risco faça parte da história humana desde há muito, encontrando-se reminiscências regulatórias sobre ele no Código de Hammurabi (século XVIII a.C.), a sua análise formal e sistemática é uma actividade 
recente da modernidade avançada (Beck, 1992). Da Renascença italiana até ao século $\mathrm{Xx}$, o risco foi ganhando relevo principalmente nas práticas comerciais e no pensamento económico, com destaque para a chamada teoria da decisão racional. A partir da segunda metade do século $\mathrm{xx}$, o discurso do risco galgou definitivamente as fronteiras da economia para tomar de assalto as ciências naturais, a psicologia, a antropologia ou a sociologia, adquirindo no processo novos significados.

Ao considerarem-se diferentes abordagens científicas do risco, não pode deixar de notar-se a ausência de uma abordagem jurídica, tanto mais difícil de explicar quanto é certo que cabe ao direito um papel capital na definição de medidas de gestão dos riscos que povoam as sociedades contemporâneas. São ainda incertos os passos que a análise jurídica vem dando em torno do estudo dos problemas de risco, apesar de o direito ser frequentemente convocado para agir sobre eles. Lidar com os riscos pressupõe uma inultrapassável dimensão regulatória dos mesmos, que os torne aceitáveis no modelo societário vigente e que acomode as exigências de segurança inerentes à convivência social e à actividade económica.

Perceber como o risco é interpretado por diferentes áreas do conhecimento e como se pode perspectivar uma leitura jurídica desse mesmo fenómeno é, por conseguinte, o propósito deste texto. Adoptando uma postura assumidamente didáctica, a sua vocação é a de servir de roteiro inicial (porque não exaustivo e não matricial) para quem pretenda tomar contacto com alguns dos discursos que se vão elaborando em torno dos problemas do risco e da incerteza.

\section{Risco objectivo e risco como construção social}

Em termos teóricos formais existe uma clivagem científica na forma de abordar os fenómenos de risco entre as teorias que adoptam uma concepção objectiva do risco e as que o encaram como uma construção social.

Para as teorias objectivistas, os riscos são realidades físicas, frequentemente mensuráveis. Para as teorias construtivistas, os riscos são arquitecturas ou artefactos sociais produzidos por indivíduos, grupos sociais ou instituições, de acordo com o contexto onde estão inseridos e os respectivos interesses e valorações.

De acordo com a concepção objectiva, os vários riscos devem ser ordenados em função do seu grau de probabilidade e da amplitude da sua lesão, e os recursos para o seu controlo devem ser aplicados prioritariamente aos riscos maiores. Segundo a concepção construtivista, a gestão do risco deve obedecer a múltiplos critérios que permitam combinar os diversos valores sociais e ajustar-se às diferentes formas de estar de uma dada sociedade 
(Renn, 1992: 54-55). Desse ponto de vista, a gestão do risco é sempre, em última instância, um processo político e de políticos (Heimann, 1997: 166).

Estas duas abordagens conceptuais demarcam as fronteiras do extenso campo teórico onde se desenvolvem as diferentes teorias sobre o risco. Como abordagens extremas, tendem a ser demasiado redutoras e excludentes. Ao reduzir-se a análise de risco a um processo de cálculo probabilístico e quantitativo, ignoram-se questões que transcendem o paradigma do actor racional, como a percepção do risco, a ambivalência da tolerância social sobre diversos riscos, a divergência sobre a perigosidade de um mesmo acontecimento para cientistas, políticos e cidadãos, etc. E quando se aposta exclusivamente na valorização das condicionantes sociais e civilizacionais, não se consegue explicar eficazmente porque razão sociedades com diferentes padrões socioeconómicos e culturais adoptam posturas semelhantes relativamente a determinados riscos.

É do confronto clássico entre estas duas concepções que emergem muitas das actuais dúvidas e interrogações teóricas e metodológicas à volta da questão do risco, apesar de quase nenhum cientista defender hoje estes paradigmas no seu estado puro, como bem reconhecem Sheila Jasanoff e Brian Wynne, ao afirmarem que "a maioria dos investigadores encara o risco simultaneamente como uma característica física e uma construção social" (apud Hellström e Jacob, 2001: 6). É o que se passa, por exemplo, com questões como as do valor que deve ser dado ao conhecimento científico, do relevo que deve merecer a percepção do risco, da imputação e partilha dos custos financeiros ou outros decorrentes da existência ou ausência de medidas de controlo do risco, da avaliação da eficácia dessas medidas, da participação alargada dos cidadãos na avaliação e gestão do risco, etc. O que parece cada vez mais evidente é o alargamento das funções de análise de risco a novos actores situados do lado de fora da 'comunidade científica' e da esfera política. As abordagens construtivistas trouxeram consigo, nas últimas três décadas, os elementos da percepção individual e colectiva do risco para dentro da análise de risco, favorecendo a transição de uma abordagem do risco tecnocrática e elitista para uma outra democrática e participada.

\section{Taxonomia das teorias do risco}

Todas as perspectivas que se ocupam do risco têm, afirma Renn (1992: 56), um elemento em comum: a distinção entre realidade e possibilidade. Se o futuro é considerado predeterminado e independente das acções humanas (concepções baseadas, por exemplo, na religião, na astrologia, etc.) então não existirá risco, mas certeza. O termo risco só faz sentido quando se possui uma visão não fatalista, não determinista da sociedade e da natureza. E esta 
é uma perspectiva relativamente recente na história da humanidade, uma conquista do Século das Luzes e da emergência do paradigma racionalista, que atribui ao homem a possibilidade de "controlar o seu destino". É esse controlo que é questionado quando se fala de uma "sociedade do risco" (Beck, 1992). O reconhecimento da possibilidade de ocorrerem danos futuros em virtude das nossas acções presentes e de que é preciso evitá-los ou atenuá-los transforma o risco num conceito simultaneamente descritivo e normativo: descreve as conexões entre causas e efeitos e as suas características, por um lado, e sugere medidas de intervenção sobre eles, por outro.

O que cada perspectiva teórica tem de diferente é precisamente a leitura que faz da realidade causal e dos cenários futuros e, consequentemente, a escolha dos objectivos e da metodologia a adoptar para lidar com eles.

\subsection{Análise quantitativa do risco}

Sob a designação de perspectiva técnica ou análise quantitativa do risco encontram-se agrupadas três teorias: a análise actuarial, a análise toxicológica e epidemiológica e a análise probabilística.

A análise actuarial tem por base o estudo da frequência com que determinados eventos se repetem ao longo do tempo. Assim, por exemplo, através da análise estatística sobre os fogos florestais registados em anos anteriores podem efectuar-se extrapolações sobre o número de incêndios que ocorrerão nos próximos anos. Os resultados esperados traduzem um valor médio calculado para um dado espaço, tempo e contexto (Renn, 1992: 58; Hellström e Jacob, 2001: 7). Trata-se de uma perspectiva unidimensional do risco, na medida em que contabiliza somente danos físicos e ignora outras perdas sofridas pelos indivíduos ou pelos grupos, como perdas sociais ou políticas. Por outro lado, ao fornecer apenas dados agregados sobre grandes segmentos da população, ignora as diferenças de exposição ao risco de cada indivíduo. No entanto, a sua simplificação da análise tem a vantagem de lhe conferir universalidade e operacionalidade em certos domínios da análise de riscos. É por isso a abordagem em que se baseia a actividade seguradora.

$\mathrm{Na}$ análise toxicológica, a avaliação dos efeitos adversos faz-se através da realização de experiências, por exemplo, com animais. $\mathrm{Na}$ análise epidemiológica essa avaliação é feita através da formulação de modelos, como é o caso da comparação entre populações expostas e populações não expostas a um determinado agente de risco (Jaeger et al., 2001: 85). O risco é, para estas teorias, uma característica dos sistemas físicos que é independente da consciência que as pessoas têm da eventual exposição a ele ou da probabilidade de virem a sofrer os seus efeitos. Estas perspectivas procuram 
apenas identificar uma relação de causalidade entre um determinado agente de risco e as pessoas ou outros seres vivos afectados por ele. A sua 'normatividade' traduz-se na protecção da saúde humana através da fixação de níveis de tolerância ao risco que limitem a exposição dos seres humanos a determinados agentes perigosos (por exemplo, fixar limiares máximos para a concentração, no ar ou na água, de determinados elementos ou compostos químicos) (Jaeger et al., 2001: 91). Tal como a análise actuarial, estas perspectivas integram também uma concepção unidimensional do risco: a lesão da saúde ou do ambiente.

Por sua vez, a análise probabilística do risco tem em vista predeterminar a probabilidade de ocorrerem falhas de segurança em sistemas tecnológicos complexos, como é o caso de uma central nuclear (Renn, 1992: 59). A avaliação da totalidade do sistema é feita com base na decomposição desse sistema nos seus componentes, desde a mais pequena peça da engrenagem até às pessoas que nele operam. O objectivo é estimar a média de acontecimentos negativos que podem vir a ocorrer num determinado período de tempo por acção do homem ou por falha tecnológica.

Todas estas perspectivas concebem a avaliação do risco como uma tarefa restrita dos peritos, enquanto especialistas dotados dos conhecimentos técnicos e científicos necessários para o efeito. Nelas não existe qualquer espaço para a participação de outros actores e de diferentes conhecimentos, o que, por sua vez, tem suscitado diversas críticas por parte dos cientistas sociais.

Uma das críticas diz respeito ao que parece ser uma excessiva simplificação das interacções entre a actividade humana e os seus resultados, reduzindo-as apenas a médias quantitativamente determinadas, calculadas num cenário de total abstracção dos processos de intermediação social e cultural que modelam a percepção do risco.

Outra crítica refere-se à abordagem unidimensional do risco, no sentido de apenas se ocuparem dos custos para a saúde e para o ambiente, ignorando prejuízos de outra natureza que são também sentidos pelas pessoas (sociais, económicos, culturais, éticos).

Apesar das críticas, reconhece-se que o papel das perspectivas técnicas é valioso para quem tem de decidir sobre o risco (geri-lo), na medida em que permitem estimar, para diferentes opções, as perdas humanas em determinados domínios, como nos transportes, na medicina ou em conflitos armados.

\subsection{Teoria da decisão racional}

A análise económica do risco foi a primeira abordagem deste com contornos sociais e situa-se a meio caminho entre a análise quantitativa e a análise social do risco. 
$\mathrm{Na}$ teoria da decisão racional, como também é conhecida a perspectiva económica neoclássica, o risco é expresso não em termos de valor esperado, mas de utilidade esperada (Bernoulli). O conceito de utilidade traduz a satisfação ou insatisfação de cada indivíduo associada aos resultados potenciais de cada acção. O risco representa as perdas esperadas de utilidade de um determinado acontecimento ou decisão, podendo enquanto tal ser avaliado através de uma análise custo-benefício.

A teoria económica introduz assim na análise do risco considerações subjectivas (probabilidade subjectiva). Espera-se que cada indivíduo tome decisões e actue tendo em vista maximizar a sua satisfação, comportando-se de forma racional.

O paradigma do actor racional admite que os indivíduos, quando na posse de informação completa, actuam de modo a maximizar os seus interesses.

No entanto, em cenários de risco e incerteza, a falta de informação completa sobre os possíveis resultados das acções empreendidas impede que sejam tomadas decisões sobre o risco com esse perfil. Por isso, uma parte do pensamento económico - a economia comportamental - veio romper com este paradigma, ao invocar os conhecimentos da psicologia para admitir que os indivíduos, devido ao conhecimento incompleto que têm da realidade e a outras limitações cognitivas, fazem muitos dos seus julgamentos com base em heurísticas (motivações pessoais, intuições, opiniões). Essas heurísticas permitem reduzir a complexidade na avaliação de probabilidades, produzindo julgamentos mais simples. Embora úteis para desbloquearem o processo de decisão individual, estas heurísticas podem gerar erros de análise. É o que sucede com os acontecimentos que vêm mais facilmente à memória e que, por isso, tendem a ser avaliados como mais prováveis do que aqueles para os quais temos maior dificuldade em invocar exemplos.

A teoria económica neoclássica oferece também uma leitura unidimensional do risco. Os seus críticos referem que esta abordagem do risco, embora permita superar algumas das limitações da análise quantitativa ao introduzir considerações subjectivas, não pode ser aplicada a todas as políticas do risco. As suas premissas baseiam-se na decisão individual e na produção de efeitos apenas sobre quem decide. Uma utilidade média será o padrão, mas, tal como se referiu a propósito da análise actuarial, isso significa que haverá sempre quem não se reveja nesse padrão. Além disso, muitas decisões podem impor riscos a terceiros que não gozam ou gozam marginalmente dos benefícios (externalidades), levantado vários problemas, nomeadamente de justiça distributiva. 


\subsection{Abordagem psicológica}

A perspectiva psicológica do risco, também conhecida como análise psicométrica ou cognitiva, centra-se nas preferências dos indivíduos. No entanto, defende que a acção humana é moldada pelas perspectivas que cada indivíduo tem do que são as consequências mais prováveis das suas decisões. Essas consequências poderão ser "reais, intuídas, irracionais ou meras fantasias” (Jaeger et al., 2001: 54). Este consequencialismo é, pois, distinto daquele que se observa na teoria da decisão racional. Tudo dependerá dos processos cognitivos através dos quais se antevêem as hipóteses de escolha e as respectivas consequências

Isto significa que, de acordo com esta perspectiva, o que importa compreender não é o modo como o risco é socialmente construído, mas a forma como as pessoas respondem ao risco (Hellström e Jacob, 2001: 9). E essa resposta nem sempre segue os padrões de decisão racional. Kanhemann e Tversky (apud Renn, 1992: 64-65) reconhecem a existência de distorções cognitivas que fazem com que, mesmo com probabilidades conhecidas, os indivíduos não sigam os padrões de racionalidade. Muitos deles não percepcionam o risco segundo uma relação de amplitude de perda ou ganho (Jaeger et al., 2001: 184). Ou seja, não procuram tanto maximizar os seus ganhos, mas sobretudo conseguir equilibrar o risco que correm, o que fazem procurando evitar grandes perdas e garantir ao mesmo tempo um nível satisfatório de ganhos. E isso é explicável porque as pessoas são mais avessas à perda em si do que ao risco (de perder ou ganhar). Esta interpretação, própria da chamada prospect theory, estabelece a ligação entre as dimensões psicológica e económica, exprimindo-se na já referida economia comportamental. Estes desvios não são o fruto da ignorância ou da irracionalidade, antes o resultado da interacção de diversas variáveis contextuais. É o caso, como já foi referido, do grau de familiaridade com o evento ou da facilidade em invocar experiências similares e também das próprias características dos riscos (frequência, consequência, carácter (in)voluntário, controlo) (Slovic, 1992). Por exemplo, alguns estudos permitiram concluir que as pessoas são mais avessas a riscos menos prováveis, mas com consequências mais graves (low-probabilitity/high-consequence), do que a riscos que, embora mais frequentes, tenham consequências de gravidade média ou baixa (high-probabilitity/low-consequence). Em 1969, depois de diversas observações, Chauncey Starr concluía que as pessoas são mais favoráveis a correr riscos voluntários como fumar ou fazer escalada, do que involuntários, como viver junto a uma central nuclear. Essa aceitabilidade chegava a ser mil vezes superior no primeiro caso face ao segundo. 
Estes factores mostram que a resposta dos indivíduos ao risco varia de acordo com a percepção que têm dele e não de acordo com as suas características objectivas ou com a sua avaliação científica. "A avaliação científica constitui uma parte da resposta dos indivíduos ao risco, na medida em que ela seja integrada na percepção individual dos mesmos" (Renn, 1992: 66).

Se as percepções variam entre indivíduos e entre grupos, isso levanta sérias dificuldades do ponto de vista da gestão do risco, pois haverá que determinar quais as percepções prevalecentes e sustentar validamente essa escolha. No entanto, esta abordagem do risco, ao introduzir no discurso científico a percepção do risco, ou seja, a valorização do reconbecimento e das preocupações que as pessoas têm do risco, ajuda a tornar as decisões sobre ele mais consistentes e próximas da realidade, e a integrar certo tipo de efeitos adversos que as perspectivas técnicas não abrangem.

\subsection{Abordagem sociológica}

Ortwin Renn (1992) identifica, dentro da análise sociológica, as seguintes teorias dominantes: teoria do actor racional (Dawes), teoria da mobilização social (MacCarthy e Zald; Watts), teoria organizacional (Perrow), teoria dos sistemas (Luhmann), teoria crítica e teoria neo-marxista (Escola de Frankfurt; Habermas; Dombrowski) e teoria construtivista social (Johnson e Covello; Bradbury; Wynne).

Segundo a perspectiva do actor racional, toda a actividade social resulta da vontade deliberada dos actores sociais (indivíduos e organizações) de satisfazerem os seus interesses, para o que mobilizam os meios necessários para tal. O conflito social emerge precisamente quando se confrontam interesses divergentes. Assim, no domínio do risco, quando um actor individual ou institucional considera que um certo risco prejudica os seus interesses, apela (activamente) à tomada de medidas políticas que impeçam ou limitem esse risco. Esta postura pode, todavia, entrar em rota de colisão com os interesses de outros actores que beneficiam da actividade que dá origem ao risco.

A teoria da mobilização social lida com o risco partindo da resposta a duas questões principais: a primeira diz respeito à determinação das circunstâncias em que os indivíduos ou os grupos sociais decidem agir, designadamente quando esteja em causa um risco; a segunda é a de quais são as condições estruturais necessárias para que a sua acção seja bem sucedida e eles atinjam os seus objectivos. Numa primeira fase, esta teoria perfilhava uma perspectiva mais individualista e baseada no conceito de actor racional. Posteriormente evoluiu para uma abordagem mais contextualista e estrutural, ao considerar que o sucesso ou insucesso de cada actor social depende muito 
mais da performance dos grupos sociais e das instituições dos quais participa, do que dos seus esforços ou estratégias pessoais.

Por sua vez, a teoria organizacional, protagonizada sobretudo por Charles Perrow, baseia-se em dois aspectos estruturais das organizações - rotinização de tarefas e difusão da responsabilidade - para mostrar que o risco real pode ser subestimado por uma análise estritamente técnica, onde o elemento humano é secundarizado. Em organizações tecnologicamente complexas como são, por exemplo, as centrais nucleares, a rotinização e dispersão do controlo do risco pode afectar negativamente a performance dos gestores desse risco, tornado os acidentes não apenas possíveis como também inevitáveis.

Para a teoria dos sistemas, de Luhmann, o risco representa um perigo que é escolhido por um actor social. Segundo ele, o oposto de risco não é segurança, mas perigo, enquanto ameaça exterior, isto é, aquela que tem origem no ambiente que envolve os sistemas sociais. $\mathrm{O}$ risco permite distinguir o inesperado do indesejado (Jaeger et al., 2001: 194). O risco é assim um elemento integrante de unidades sociais e institucionais mais amplas que são os sistemas sociais. Nessa medida, faz parte do processo evolutivo através do qual os grupos sociais e as instituições organizam o seu conhecimento do ambiente natural e social que os rodeia. Os sistemas sociais formam-se a partir da fixação de normas sociais que delimitam os sistemas face ao ambiente que os rodeia. Essas normas são sempre transitórias e contingentes, o que faz dos sistemas estruturas dinâmicas e sempre em risco de dissolução (Jaeger et al., 2001: 194). No entanto, uma das funções dos sistemas é precisamente a de conceder aos indivíduos a compreensão não só dos eventos inesperados (perigos), mas também dos efeitos indesejados (riscos) de uma determinada acção.

Para as teorias neo-marxista e crítica, o que importa não é tanto a compreensão das experiências e políticas de redução do risco, mas a sua dimensão emancipatória, ou seja, como dotar os diferentes grupos sociais do poder necessário para serem eles a determinar o seu nível de risco tolerável. Estas perspectivas reconhecem no risco duas características típicas da sociedade actual: uma crise de legitimidade política, na medida em que os riscos são impostos por um grupo social a outro, frequentemente apenas no interesse do primeiro; a reprodução, também nesta matéria, de uma sociedade estruturada em classes, com distribuição desigual do poder e da influência social e, consequentemente, do risco e dos seus resultados.

Finalmente, a teoria construtivista social considera o risco como uma construção social determinada pelas forças estruturais da sociedade. Cada grupo social efectua essas construções segundo os seus interesses e valores 
grupais ou institucionais e procura depois colocá-los na linha da frente da agenda política. Assim, as políticas do risco não são mais do que o produto da luta constante entre os vários actores que participam nas diversas arenas político-sociais, resultando assim das supremacias ou dos consensos alcançados. Neste contexto, a predominância da análise técnica do risco não será mais do que uma construção do risco que é feita por elites científicas, segundo as suas convenções de grupo, os seus interesses e os seus valores.

Todas estas perspectivas comungam do entendimento de que as consequências reais (risco objectivo) são sempre mediadas por interpretações sociais (percepções) e modeladas pelos valores e interesses de cada grupo social. Por isso, uma análise probabilística do risco deve ser acompanhada das leituras específicas que dele são feitas pelos grupos e instituições que se movimentam e operam num dado espaço ou arena. Só essa integração permite que, além da minimização do risco, sejam ponderados outros objectivos nas políticas do risco, como questões de "equidade, justiça, flexibilidade e resiliência“ (Hellström e Jacob, 2001: 10).

\subsection{Abordagem cultural}

Enquanto a análise sociológica do risco relaciona as construções sociais do risco com os valores e interesses dos indivíduos ou dos grupos sociais, a teoria cultural, de matriz antropológica, defende que são os padrões culturais que estruturam as opções dos indivíduos e dos grupos/instituições, levando-os a aceitar determinados valores e a rejeitar outros. São esses valores assim seleccionados que determinam a percepção do risco. Cada sociedade produz o seu próprio entendimento do mundo, do ambiente que a rodeia, e esse entendimento influencia por sua vez a escolha dos riscos que captam a atenção e mobilizam os membros da sociedade.

A teoria cultural não nega a existência objectiva do risco (Douglas, 1992: 29), mas encara-o como um elemento que só adquire relevo quando é mediatizado através do ambiente social, político e ético que o envolve, como forma de criticar determinados aspectos da própria sociedade. Para os defensores da teoria cultural, o risco é um conceito construído pelas sociedades modernas, em resultado de uma maior consciência deste, mesmo que objectivamente não existam mais perigos do que no passado (Furedi, 1998: 8).

$\mathrm{Na}$ sociedade concorrem, assim, várias "racionalidades", ou seja, diversos padrões culturais ou ideologias que traduzem uma dada perspectiva da sociedade (de como ela deve ser estruturada) e que são formados pelas crenças e pelos valores de cada um. Cada padrão cultural é cego a determinadas coisas e sensível a outras (Jaeger et al., 2001: 185). A cultura oferece aos indivíduos uma linha de orientação no mundo em que vivem, através 
da definição de sistemas classificatórios e organizatórios. Deste modo, o risco é compreendido (percebido) à luz da sua relação com os princípios básicos de cada cultura. Quando esse risco não ameaça esses princípios, ele é considerado aceitável e pode ser gerido do ponto de vista individual, através de uma análise custo-benefício. Quando põe em causa os pressupostos culturais vitais, o risco é tido por inaceitável e não pode ser gerido a título individual, mas colectivo (Jaeger et al., 2001: 188).

Ao fazer uma leitura diferenciada da sociedade, admitindo diversos padrões culturais que traduzem outras tantas formas diferentes de encarar o risco, e ao enfatizar os valores e perspectivas individuais e organizacionais e não apenas as utilidades esperadas ou o risco em termos físicos, a teoria cultural oferece uma leitura mais rica e complexa da realidade social, que torna mais completa a análise dos riscos. Contudo, a sua pretensão de auto-suficiência e o seu imperialismo ou determinismo cultural suscitaram críticas de outros cientistas sociais. A mais importante parece ser a que se prende com o facto de esta perspectiva proporcionar uma interpretação estática e segmentada da realidade social, ignorando que o mesmo actor pode, num contexto, comportar-se como um individualista e noutro contexto completamente diferente assumir uma postura tipicamente igualitária (Renn, 1992: 75). Será o caso, por exemplo, de um empresário que procura obter o máximo sucesso com o seu negócio e que, simultaneamente, presta serviço como voluntário numa associação de beneficência. Os padrões culturais apresentados descrevem as posturas dos indivíduos e/ou grupos em determinados contextos sociais (Jaeger et al., 2001: 189). A mobilidade é a regra e não a excepção.

\section{O direito e o risco: da intervenção ex post à regulação ex ante}

\subsection{Os cânones clássicos da responsabilidade civil e criminal}

Os primeiros contactos sistemáticos do direito com o risco fizeram-se por intermédio do instituto da responsabilidade.

Historicamente, a primeira formulação da responsabilidade era objectiva, no sentido de que não importava "que o dano resultasse de uma acção intencional ou negligente ou de um caso fortuito" (Júnior, 2003: 179). A responsabilidade tinha sobretudo um carácter ético-retributivo, em que se procurava vingar a ofensa recebida, não se levando em conta a distinção entre causas e efeitos nem entre delitos civis e criminais. Com o tempo, a responsabilidade foi ficando imbuída da ideia de culpa, pressuposto imprescindível da responsabilidade.

Quando há um prejuízo, este não deve ficar a cargo da pessoa em cuja esfera foi produzido, devendo antes impor-se a obrigação do seu ressarci- 
mento à pessoa cujo comportamento provocou tal lesão na esfera de outrem (Varela, 2000: 630). Assim, quando a lei impõe ao autor de certos factos ou ao beneficiário de certa actividade a obrigação de reparar os danos causados a outrem por esses factos ou essa actividade, surge a figura da responsabilidade civil, figura que actua, portanto, através do surgimento da obrigação de indemnização.

Indemnizar visa justamente tornar indemne o lesado, ou seja, colocá-lo na situação em que se encontraria se não tivesse ocorrido o facto danoso. Esse facto torna a responsabilidade civil, nas palavras de Tanzi e Delmer (2006: 64) "um poderoso regulador de todo o desvio social susceptível de criar um risco."

O nosso Código Civil mantém-se fiel à regra comum a outros ordenamentos jurídicos de que não há responsabilidade sem culpa (cf. art. $483^{\circ}$ ). Sofrendo alguém danos na sua esfera jurídica, só lhe será possível ressarcir-se à custa de outrem relativamente àqueles danos que, provindo de facto ilícito, sejam imputáveis a conduta culposa de terceiro.

Contudo, uma responsabilidade civil exclusivamente adstrita ao pressuposto da culpa do agente ou lesante acabaria por deixar sem resposta vários domínios da conflitualidade social.

A confrontação dos limites da responsabilidade clássica com novas exigências da vida social dá-se quando se modernizam os processos de fabrico, por meio da industrialização. A revolução industrial trouxe consigo a afluência, mas também gerou um aumento do número (e gravidade) dos acidentes de trabalho. A desigualdade de poderes entre entidades patronais e assalariados fazia com que estes tivessem enorme dificuldade em exigir daquelas uma indemnização pelos danos sofridos com os acidentes, dentro dos moldes tradicionais da responsabilidade civil.

Neste contexto, a ciência jurídica acabaria por avançar para uma nova teoria da responsabilidade: a teoria do risco.

A responsabilidade pelo risco ou responsabilidade objectiva dispensa entre os seus pressupostos a culpa do agente, ou seja, o elemento subjectivo traduzido no nexo psicológico entre o facto praticado e a vontade do lesante.

Do que se pode perceber sobre a evolução da teoria da responsabilidade, com uma relativa erosão do princípio da culpa e um engrandecimento da responsabilidade objectiva, a denominação que a esta última se dá de responsabilidade pelo risco não comunga, em bom rigor, de nenhuma ideia de probabilidade ou frequência de um qualquer efeito adverso, como é comummente entendido quando se fala de risco noutras áreas científicas. O que seja esse risco não nos é dito, senão pela sua consumação plena em dano. É que, à semelhança do que sucede com a responsabilidade baseada na 
culpa, a responsabilidade objectiva ou pelo risco só é accionada quando uma ameaça se materializa, não bastando a simples probabilidade (estatística) da sua concretização. Há, contudo, uma evolução da própria responsabilidade objectiva que sugere uma atenção diferente à questão do risco. Trata-se de algumas manifestações de socialização (pública ou privada) de determinados acontecimentos, como os acidentes de viação e os acidentes de trabalho, traduzidos em sistemas de securização ou mutualização e de protecção social. Uma vez mais, o que está em causa é o ressarcimento das vítimas de acidentes rodoviários e laborais, o que implica sempre a produção efectiva de um determinado prejuízo. Contudo, o legislador, apercebendo-se da generalização destes comportamentos de risco (condução de veículos e utilização de mão-de-obra), aos quais subjaz a referida utilidade social, e reconhecendo a sua materialização frequente em dados reais, entendeu por bem impor medidas não exactamente de diminuição desse risco, mas de minimização dos seus efeitos negativos (possibilitar, por exemplo, a reparação do veículo do lesado).

Ao contrário do que sucede com a responsabilidade civil, em que o que se pretende é restabelecer os interesses privados do lesado, na responsabilidade criminal tem-se em vista satisfazer os interesses da comunidade afectada por um facto ilícito criminal, dotado de especial gravidade. ${ }^{1}$

O direito penal começou por ver ser-lhe atribuída uma faceta ético-retibutiva e, por isso, necessariamente repressiva e a posteriori. Evoluiu depois para outros modelos, assentes numa visão mais utilitarista da função criminalizadora. Primeiro, incorporou uma ideia de prevenção especial, procedente do Iluminismo, segundo a qual a pena não tem em vista retribuir o facto passado, mas prevenir a prática de novos delitos pelo agente. Já no início do século XIX seria a vez da ideia de prevenção geral se afirmar na tutela penal. Encaradas como instrumento de prevenção geral, as penas apresentam-se como "instrumentos político-criminais destinados a actuar (psiquicamente) sobre a generalidade dos membros da comunidade, afastando-os da prática de crimes através das ameaças penais estatuídas pela lei, da realidade da aplicação judicial das penas e da efectividade da sua execução" (Dias, 1996: 84). A pena é assim encarada como forma de intimidação das pessoas, dissuadindo-as da prática de crimes.

Como reconhece Figueiredo Dias (1996), não se pode afirmar que a prevenção em direito penal - pelo menos na vertente individual - tenha uma natureza apriorística, uma vez que não há lugar à aplicação de uma pena sem que haja um crime. A prevenção especial só funciona necessariamente

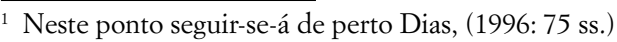


depois da prática efectiva de um crime e nunca antes. $\mathrm{O}$ risco que se pretende prevenir é o da reincidência do agente na prática criminal.

A prevenção geral, contudo, conforma-se mais com o conceito de risco que aqui se adoptou. A prática de determinados indivíduos mostra que o risco de lesão de bens jurídico-penais é uma probabilidade (cujo grau não se aprecia aqui), que justifica a adopção de medidas tendentes a impedir a sua verificação ou limitar os seus efeitos no contexto da sociedade. Essas medidas não se esgotam apenas na enunciação de tipos legais de crime e respectivas cominações, mas revelam-se sobretudo na punição efectiva dos infractores, de forma a intimidar e afastar da prática do crime os demais.

A responsabilidade penal não se aproxima da ideia de risco apenas quando se pondera a questão dogmática dos fins das penas. Ela ocorre também quando se observam os próprios tipos legais de crime. Além dos chamados crimes de dano - aqueles que pressupõem a efectiva produção de uma lesão a bens jurídicos criminais - existem também os crimes de perigo (concreto e abstracto), quando esses bens são apenas colocados numa situação em que é possível a ocorrência da lesão (Costa, 1991: 583). Neste caso, a responsabilidade decorre de haver um risco de lesão e não uma lesão efectiva, como sucede nos demais casos. Atente-se, por exemplo, no art. $280^{\circ}$ do Código Penal português (Poluição com perigo comum), onde o agente será punido se, com a sua conduta - poluir -, criar uma situação de especial vulnerabilidade para a vida, a integridade física ou o património de terceiros de valor elevado.

A introdução, no direito penal, dos crimes de perigo faz parte de um movimento de neocriminalização de certos domínios da vida social, designadamente dos que se referem à protecção do ambiente (cf., o já citado art. $280^{\circ}$ do Código Penal) e dos consumidores (cf., por exemplo, o art. $282^{\circ}$ do Código Penal, sobre corrupção de substâncias alimentares e medicinais), e que decorre do progresso técnico e tecnológico das sociedades contemporâneas e dos seus reflexos negativos na vida humana e na natureza. Esse movimento não é mais do que o reflexo da abertura do direito penal às novas demandas da sociedade de risco, traduzida num princípio de antecipação da protecção penal e na consagração supra-individual (colectiva ou difusa) de novos bens jurídico-penais (Dias, 2001: 16).

\subsection{Os princípios jurídicos da prevenção e da precaução}

Por tudo o que se disse já, percebe-se que o discurso jurídico não tem permanecido imune à questão do risco. O desenvolvimento económico e tecnológico, com os seus benefícios, mas também com os seus efeitos nocivos, e a intensificação e complexificação das relações sociais, onde o valor da segu- 
rança e a tolerância ao risco se associam numa demanda de respostas políticas e regulatórias eficazes, pressionou os quadros jurídicos clássicos, levando-os a introduzir modificações em institutos pré-existentes, como é o caso da responsabilidade.

Contudo isso não bastou e a pressão sobre o jurídico não parou de crescer, forçando-o a abordagens mais orientadas para a vertente da prevenção do dano, voltando a atenção para as causas, e não apenas a da sua reparação. Mas o enfoque na causalidade serviu igualmente para trazer novos problemas. A progressiva constatação dos limites da certeza e verdade do conhecimento científico, nomeadamente quando se trata da produção de prova, e sobre o seu papel e o seu valor nos processos de análise de riscos ampliou as interrogações e suscitou novos apelos ao direito, no sentido da incorporação de medidas eivadas de um sentido precautório.

É, pois, na resposta aos desafios de uma intervenção preventiva e antecipatória que se estreita a relação entre o risco e o direito. Não está em causa, no entanto, uma conceptualização jurídica e muito menos legalista do risco, apenas uma juridificação da gestão de certos riscos, através da intervenção de actores, instrumentos e metodologias originários do direito.

O princípio da prevenção funciona como uma alternativa à perspectiva clássica da reparação do dano. A irreversibilidade de alguns danos, como os danos ambientais (extinção de espécies, perda de biodiversidade, etc.), e a gravidade potencial das lesões para os direitos e interesses dos consumidores decorrente de certos produtos - mormente dos produtos defeituosos e perigosos - não se pode bastar com a adopção de medidas meramente curativas ou repressivo-correctoras. A irreparabilidade de certos danos tornará mais eficaz e menos onerosa uma política baseada em medidas preventivo-antecipatórias (Canotilho, 1995: 40).

A intervenção do princípio da prevenção funda-se na certeza científica e no cálculo probabilístico sobre a medida da verificação de determinados efeitos negativos, mesmo que essa medida não seja em absoluto identificável no momento. Isso faz dele o princípio de eleição na abordagem ao risco. Em cenário de risco, competentemente avaliado, impõe-se uma intervenção preventivo-proactiva no sentido de o eliminar ou pelo menos minorar. A prevenção constrói-se sobre 'o terreno firme do conhecimento' para impor aos decisores políticos um dever de agir (e não de reagir) sobre a origem do risco (o perigo) e as suas consequências (a lesão).

Já o princípio da precaução tem merecido uma atenção muito especial da parte de vários autores, muitos dos quais nem sequer da área jurídica. Este princípio jurídico e político é hoje um dos aspectos mais debatidos pelas teorias do risco, em particular quando se discutem os limites e insuficiências 
do conhecimento científico na identificação e avaliação dos riscos pouco ou nada conhecidos, isto é, da incerteza. Autores como Sunstein (2005: 4) acusam-no de ser um princípio (jurídico e político) paralisante da acção governativa (governement) e do desenvolvimento económico e tecnológico, quando levado ao extremo. Levá-lo ao extremo significa encará-lo como uma regra de abstenção que inibe toda e qualquer medida regulatória ou actividade económica por falta de informação absolutamente certa e fiável sobre os seus efeitos relativamente à humanidade e ao ambiente. Ora, é precisamente porque não se sabe que é preciso agir, sustentam outros autores (Ewald et al., 2001: 26). O que se pretende é uma atitude de prudência, não de renúncia. Kourilsky (2002: 156) sugere mesmo que, se persistir uma apropriação do princípio pelas 'garras' do imobilismo e da abstenção, há que fazer-lhe frente e ter a coragem de abandoná-lo. Paradoxalmente, este é um princípio que decorre das exigências de segurança e de certeza que todos reclamam, mas que, ao mesmo tempo, é o exemplo acabado da insegurança e incerteza que povoam a sociedade actual e o conhecimento científico que, desde o século XIX, servira de referencial à organização da vida social e do pensamento racional.

\subsection{Uma não-conclusão: o desafio de uma abordagem mais comprometida do direito com o risco}

Do exposto percebe-se que o direito, apesar de não avançar com um conceito (jurídico) de risco, admite implicitamente que o risco existe e que é susceptível de se consumar na produção de danos muitas vezes irreversíveis e irreparáveis.

O direito encara o risco sobretudo como objecto da regulação jurídica. ${ }^{2}$ Nesta perspectiva, o risco é encarado como o quid sobre o qual se exerce a missão reguladora do direito, como o problema ou o conflito que exige uma solução capaz de restabelecer o equilíbrio e a segurança na sociedade. $\mathrm{O}$ risco, enquanto potencial de ameaça de lesão a bens e interesses dos indivíduos e da colectividade, cria um conflito social que exige a sua pacificação por meios lícitos e legítimos. Ora, nas sociedades contemporâneas, o direito oferece-se como um sistema privilegiado para exercer essa função pacificadora. Nessa medida, o risco surge como um corpo que, sendo estranho ao jurídico enquanto conceito ou instituto, se apresenta com enorme actualidade e importância enquanto enfoque da sua intervenção.

\footnotetext{
${ }^{2}$ Não se cuida aqui de discutir o conceito de regulação e a sua correspondência ou não com o conceito de direito. Sobre essa questão, cf. Black, (2004: 34).
} 
No entanto, é possível sustentar uma abordagem adicional do direito face ao risco, mais desafiadora e actualista, segundo a qual o risco é entendido também como modo de produção da regulação jurídica. Nesta medida, o risco funciona como uma matriz e um caminho por meio do qual a regulação pode exercer a gestão de determinados problemas da sociedade actual. Jenny Steele (2004: 44) refere-se ao risco como uma técnica de governação e de regulação próprias da sociedade de risco em que vivemos. Nesta perspectiva, o risco confronta directamente o papel do direito como gestor, não já na medida em que este define determinados parâmetros tendentes a minimizar o risco (enquanto objecto), mas na medida em que tal o obriga a trilhar novas estratégias regulatórias com vista à tomada de decisão e à realização de escolhas num cenário precário e inconstante. Assim sendo, o risco afigura-se como um modo de conceber e interpretar o próprio processo regulador. Steele (2004: 7-9) sublinha precisamente a ligação primária fundamental que o risco mantém com o processo de decisão. Ao fazer do risco não apenas o objecto regulado, mas um postulado da função regulatória, o direito deixa de agir sobre ele de um modo meramente exterior, incidental e fragmentado, como sucede no caso da responsabilidade. Para Thomas Wilhelmsson (2007: 9), na sociedade do risco é necessário um direito disponível para aprender ("learning law"), um direito que seja capaz de se adaptar rapidamente às sucessivas experiências que a sociedade enfrenta com a emergência de novos problemas de risco.

Deixando-se guiar pela abordagem do risco, o regulador consegue libertar-se com proveito da dicotomia entre risco objectivo e risco como construção social, apropriando-se do que vantajosamente é dado por cada um dos paradigmas. Por um lado, pode continuar a apoiar-se no saber científico e colher nele o conhecimento de base sobre a dimensão do risco e as suas características sem, contudo, perder de vista que este conhecimento pode ser insuficiente e efémero, à medida que novos progressos de investigação vão surgindo (uma vez mais emerge a ideia do direito que está disponível para aprender). Por outro lado possibilita-lhe atender às angústias, aos receios dos cidadãos, mas distinguindo o que é um temor justificado de receios exagerados ou fantasiosos. Segundo Sunstein (2005: 1), o Estado não responde a medos triviais e infundados da opinião pública através de medidas para reduzir o risco, mas recorrendo a mecanismos de formação e informação capazes de mostrar a inconsistência desse receio.

Fazer do risco um postulado da função regulatória obriga também o regulador a actuar quando os riscos são pouco salientes ou escassamente valorizados pela opinião pública, embora sejam reais, ou quando se des- 
conhece a medida do risco, as suas consequências ou sequer a sua probabilidade (Sunstein, 2005: 226).

Encarar a regulação pela vertente do risco é simultaneamente libertá-la - das paixões da sociedade e dos espartilhos da ciência - e responsabilizá-la - obrigando-a a forjar-se quando o cenário é de dúvida ou quando a consciência pública do risco é baixa ou nula. É isso que significa a regulação do risco. A regulação do risco corresponde à intervenção governamental nos processos sociais e de mercado com vista a controlar os efeitos adversos potenciais decorrentes desses processos (Hood et al., 2001: 3). Para John Applegate (2004: 79), a regulação orientada pelo risco permite uma intervenção ex ante sobre o perigo colectivo, em vez de uma acção ex post sobre o dano individual, contribuindo desta forma para a prevenção dos danos colectivos.

Em síntese, reconhece-se que o direito, ao contrário de outras disciplinas científicas, não cuida de definir o risco, antes lhes pede 'emprestado' o conceito de risco que é chamado a regular. Mas nem por isso o direito deixa de ter um papel activo na definição das medidas de gestão dos riscos naturais e industriais. Tradicionalmente, a sua preocupação sempre esteve muito mais voltada para as consequências da consumação do risco, ou seja, para os danos, e para a sua imputação, do que para a sua conceptualização e prevenção.

O desafio estará precisamente em perceber de que forma o direito é levado a lidar hoje com os problemas de risco, como se emancipa das suas posturas mais clássicas de uma intervenção ex post no conflito, em prol de uma abordagem mais ampla, de regulação ex ante (prevenção do próprio conflito). E aí existe ainda um longo caminho a percorrer pelo pensamento jurídico.

\section{Referências bibliográficas}

Applegate, John (2004), "The Perils of Unreasonable Risk: Information, Regulatory Policy, and Toxic Substances Control", in John Applegate (org.), Environmental Risk, I. Burlington: Ashgate, 67-139.

Beck, Ulrich (2000), "Risk Society Revisited. Theory, Politics and Research Programmes", in Barbara Adam et al. (orgs.), The Risk Society and Beyond. Critical Issues for Social Theory. Londres: Sage.

Beck, Ulrich (1992), Risk Society: Towards a New Modernity. Londres: Sage

Black, Julia (2004), "Law and Regulation: the Case of Finance", Christine Parker et al. (orgs.), Regulating Law. Oxford: OUP, 33-59.

Black, Julia (2002), Critical Reflections on Regulation. Londres: CARR/LSE. 
Canotilho, Joaquim Gomes (1995), Direito Público do Ambiente (Direito Constitucional e Direito Administrativo). Coimbra: CEDOUA.

Costa, José de Faria (1991), O perigo em Direito Penal. Coimbra: Coimbra Editora.

Dias, Jorge de Figueiredo (2001), Temas Básicos da Doutrina Penal. Sobre os Fundamentos da Doutrina Penal. Sobre a Doutrina Geral do Crime. Coimbra: Coimbra Editora.

Dias, Jorge de Figueiredo (1996), Direito Penal. Questões fundamentais: a doutrina geral do crime. FDUC, policop.

Douglas, Mary (1992), Risk and Blame: Essays in cultural theory. Londres: Routledge.

Ericson, Richard; Haggerty, Kevin (1997), Policing the Risk Society. Toronto: University of Toronto Press.

Ewald, François et al. (2001), Le Principe de Précaution. Paris: Puf.

Furedi, Frank (1998), Culture of Fear: Risk-taking and the Morality of Low Expectation. Londres: Cassell.

Giddens, Anthony (2000), O mundo na era da globalização. Lisboa: Editorial Presença.

Heimann, Clarence Fredrick (1997), Acceptable Risks. Politics, Policy and Risk Technologies. Michigan: University of Michigan Press.

Hellström, Tomas; Jacob, Merle (2001), Policy Uncertainty and Risk: Conceptual developments and approaches. Boston: Kluwer.

Hood, Christopher et al. (2001), The Government of Risk. Understanding Risk Regulation Regimes. Oxford: Oxford University Press.

Jaeger, Carlo C. et al. (2001), Risk, Uncertainty and Rational Action. Londres: Earthscan.

Júnior, Eduardo dos Santos (2003), Da responsabilidade civil de terceiro por lesão do direito de crédito. Coimbra: Almedina.

Kourilsky, Philippe (2002), Du bon usage du principe de précaution. Paris: Odile Jacob.

Leiss, William; Hrudey, Steve E. (2005), “On Proof and Probability: Introduction to "Law and Risk"”, Law Commission of Canada. Law and Risk. Toronto: UBC Press.

Renn, Ortwin (1992), "Concepts of Risk: A Classification”, in Sheldon Krimsky; Dominic Golding (orgs.), Social Theories of Risk. Westport: Praeger, 53-80.

Rohrmann, Bernd; Renn, Ortwin (2000), "Risk Perception Research. An Introduction”, in Ortwin Renn; Bernd Rohrmann (orgs.), Cross-Cultural Risk Perception. A Survey of Empirical Studies. Dordrecht: Kluwer, 55-102.

Slovic, Paul (1992), "Perception of Risk: Reflections on the Psychometric Paradigm", in Sheldon Krimsky; Dominic Golding (orgs.), Social Theories of Risk. Westport: Praeger

Steele, Jenny (2004), Risks and Legal Theory. Portland: Hart Publishing.

Sunstein, Cass R. (2005), The Laws of Fear. Beyond the Precautionary Principle. Cambridge: Cambridge University Press. 
72 | Catarina Frade

Tanzi, Tullio; Delmer, Frédéric (2006), Ingénierie du risque. Paris: Hermès-Lavoisier. Varela, João Antunes (2000), Das obrigações em geral. Coimbra: Almedina.

Wilhelmsson, Thomas (2007), The Paradox of the Risk Society and the Fragmentation of Consumer Law, in Iain Ramsay et al. (orgs.), Consumer Risk and Choice in Consumer Society. Atenas: Sakkoulas/Bruylant, 1-21. 